\title{
Eco-efficient manufacturing process for fibre reinforced thermoplastic
}

\author{
K. Tanaka ${ }^{1}$, T. Katayama ${ }^{1} \&$ K. Uno ${ }^{2}$ \\ ${ }^{I}$ Department of Mechanical Engineering, Doshisha University, Japan \\ ${ }^{2}$ Marubeni Co., Ltd., Japan
}

\begin{abstract}
Carbon fibre reinforced plastics (CFRP) have been applied mainly for aerospace applications. For automotive applications, they are not really used due to the high cost. The use of composites in automotive applications requires specific focus on manufacturing and cost constraints. In this study, the carbon fibre reinforced thermoplastics (CFRTP) process using high-speed processing by the electromagnetic induction (IH system) in combination with non-woven stitched multi-axial cloth (NSMC) was proposed. The IH system allows heating of the tooling surface instantaneously. Therefore, this system also can reduce production cycle times and the cost of manufacturing composite applications. Using the IH system, only about 60 seconds is needed to raise the mould temperature from $25^{\circ} \mathrm{C}$ to $250^{\circ} \mathrm{C}$, and the production cycle time can be drastically reduced.
\end{abstract}

Keywords: carbon fibres, thermoplastic resin, non-woven fabric, stitching, nonwoven stitched multi-axial cloth (NSMC), electromagnetic induction, bending strength.

\section{Introduction}

It is necessary to reduce weight in automobiles in order to obtain better gasoline mileage. The use of carbon fibre reinforced plastic (CFRP), which is one of the solutions in reducing the weight of automotive applications, requires specific focus on manufacturing and cost (Carney [1]).

The traditional method of producing composite parts where the fibre lay-up is controlled is to lay up pre-impregnated unidirectional fibre tapes on the mould tool in the desired stacking sequence. After this lay-up process, the parts will be 
cured in an autoclave. This process has only been accepted in the military aerospace industry and the non-mass-produced racing car industry due to its high cost. To overcome the cost problem related to the use of the unidirectional prepreg, multi-axial multi-ply fabric (MMF) or non-crimp stitched fabric (NCF) has been developed and has become popular owing to its advantage in rapid and precise lay-up (Lomov et al. [2] and Truong et al. [3]).

When CFRP is used for mass-produced automotive parts, thermoplastic resins have an advantage owing to their recyclability and productivity. For the mass production of thermoplastic composites using MMF, compression moulding has a superior advantage in the moulding cycle. In the compression moulding process, the method of resin supply is one of the key issues. In order not to outweigh the advantages of MMF, such as easy fitting to the mould, a novel resin supply system is expected to be developed.

For the compression moulding of thermoplastic composites, there are two ways of heating, namely preheating the materials and heating the mould. The moulding process of preheating the materials is applied to glass-mat reinforced thermoplastic (GMT). For the thermoplastic composites using MMF with precise shape and high mechanical performance, however, direct control of the mould temperature is needed. The conventional heating system, which needs a lot of energy and moulding time, is not an ecological process and the innovative mould heating system is expected to be developed.

Recently we have developed a novel material system: multi-axial multi-ply carbon fabric/non-woven fabric (non-woven stitched multi-axial cloth; NSMC, Benny-Toyama Co. Ltd., Japan). Carbon yarns, which are placed parallel to each other in separate layers of different orientation, and non-woven fabric, are all stitched together. In this material system, non-woven fabric plays the role of a supporting material to MMF and at the same time will be the matrix in the composites. Owing to the flexibility in the shape of non-woven fabric and MMF, NSMC is easy to fit to the complex shape of the mould. With regard to the moulding process, Roctool Co. Ltd. in France recently developed high-speed processing using electromagnetic induction. Using this high-speed processing, the ecological manufacturing process of fibre reinforced thermoplastic can be achieved.

In this paper, we propose a carbon fibre reinforced thermoplastics (CFRTP) process using the high-speed processing by electromagnetic induction in combination with non-woven stitched multi-axial cloth (NSMC). The advantage of our proposed process is discussed.

\section{Ecological manufacturing process}

\subsection{Non-woven stitched multi-axial cloth}

One of the difficult and important issues of the composites process is resin impregnation. Multi-axial multi-ply carbon fabric/polyamide 6 non-woven fabric (non-woven stitched multi-axial cloth; NSMC, Benny-Toyama Co. Ltd., Japan) was used in this study. The schematic drawing of this material is shown in fig. 1. 
Carbon yarns, which are placed parallel to each other in separate layers of different orientation, and polyamide 6 non-woven fabrics are all stitched together. In this material, non-woven fabric will be the matrix in the composites. NSMC makes the lamination process easier than MMF because carbon fabric and polyamide 6 non-woven fabric are stitched in one sheet, which leads to a reduction in the production cycle time.

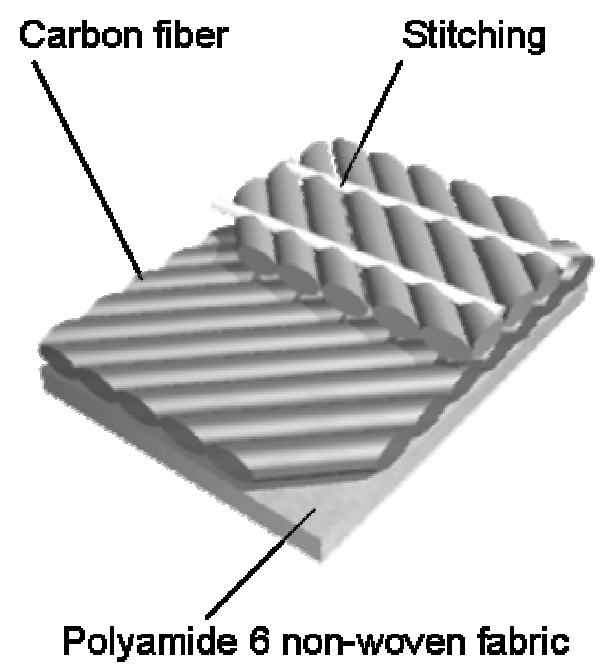

Figure 1: Schematic drawing of non-woven stitched multi-axial cloth (NSMC).

\subsection{High-speed processing using electromagnetic induction}

For the moulding process, high-speed processing using the electromagnetic induction (IH system) developed by Roctool Co. (Cage System $\left.{ }^{\circledR}\right)$ was used. Fig. 2 shows the mould and the schematic drawing of the IH system. When an electrical current runs through an inductor, a magnetic field will be generated. The magnetic field penetrates the mould placed inside the inductor, and creates induced currents on the mould surface. The current flow generated on the mould surface is shown in fig. 2(c). Since the current concentrates within the mould surface, the mould surface generates heat by the Joule effect. The principal advantage of the IH system is that the heat source is located close to the material (Guichard et al. [4]). This high-speed processing allows heating of only the mould surface by the skin effect, instantaneously. Therefore there is no need to preheat the mould or the materials before placing them in the mould.

The temperature history of the mould surface shown in fig. 2(a) during the moulding process is shown in fig. 3. Because the IH system heated only the surface of the mould, this system only required about 60 seconds to heat the mould temperature from $25^{\circ} \mathrm{C}$ to $250^{\circ} \mathrm{C}$. Due to the small heat capacity of the mould, the cooling of the mould finished in about 120 seconds. By using the IH system, composite parts can be moulded in several minutes. 


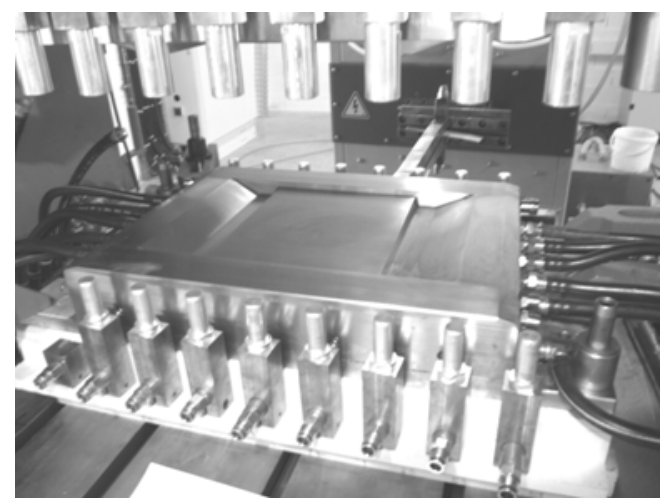

(a) Mould with IH system

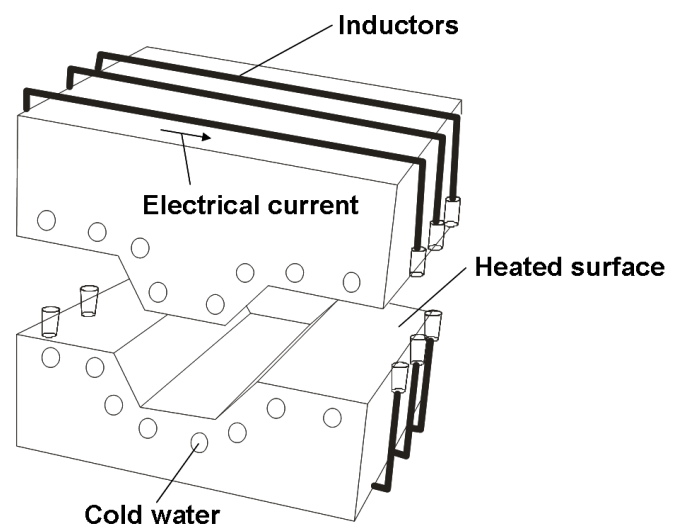

(b) Schematic of IH system

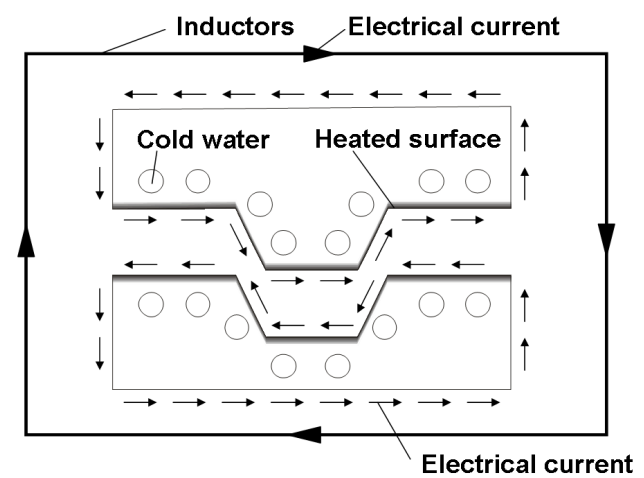

(c) Current flow of IH system

Figure 2: Mould and schematic drawing of the IH system. 


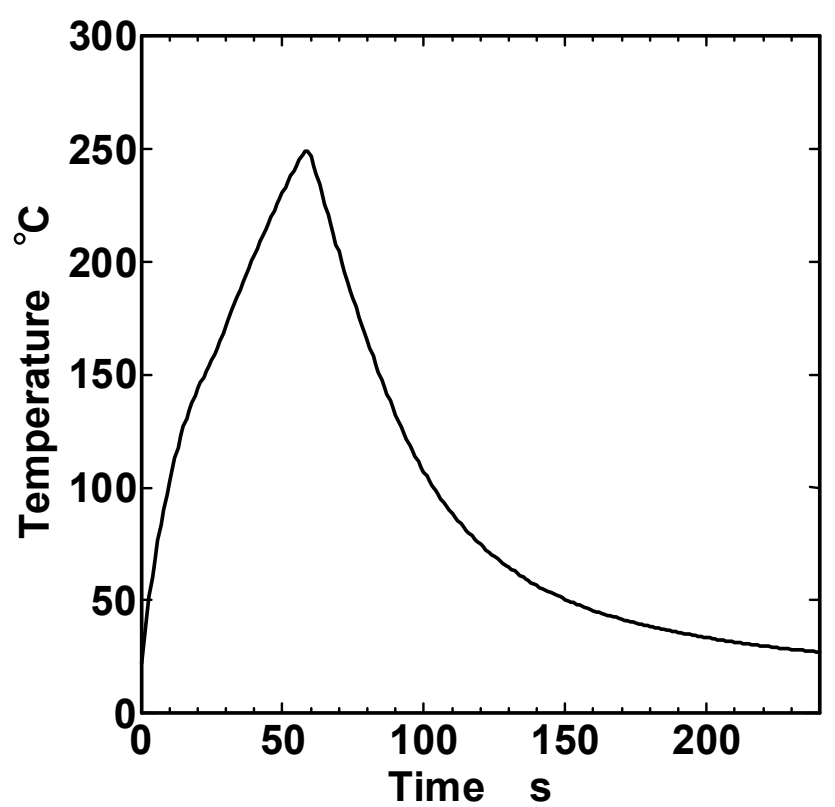

Figure 3: $\quad$ Temperature history of mould surface.

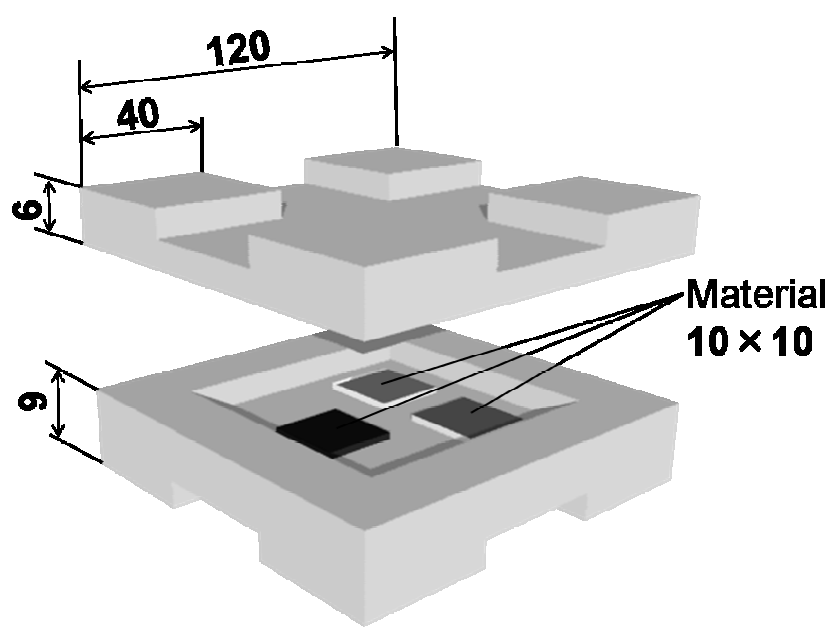

Figure 4: $\quad$ Schematic of Teflon ${ }^{\circledR}$ box. All dimensions are in $\mathrm{mm}$.

To understand the superior advantage of the IH system in combination with carbon fibre, the temperature history during the moulding process was measured. A box made of Teflon ${ }^{\circledR}$ as shown in fig. 4 was fixed in the mould of the IH system and the temperature history of the materials in the box was measured. Multi-axial multi-ply carbon fabric, glass fabric, jute fabric and aramid fabric 
were placed in the box. The temperature histories are shown in fig. 5. The temperature of all fabrics except the carbon fabric was lower than that of the surface of the Teflon box. The temperature of the carbon fabric, on the other hand, was about $10^{\circ} \mathrm{C}$ higher than that of the Teflon surface. This result indicates that not only the mould surface but also the carbon fibre itself was heated by the IH system.

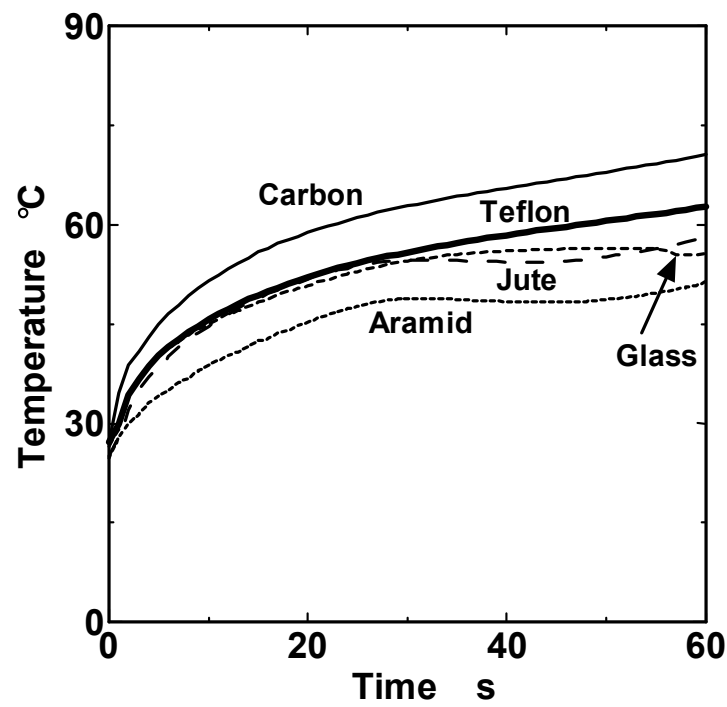

Figure 5: $\quad$ Temperature history of fabrics and surface of the Teflon box.

\section{Mechanical properties of moulded parts}

\subsection{Materials and experimental procedure}

Quadriaxial carbon fabric/polyamide 6 non-woven fabric (NSMC) was used in this study. The weight per unit area of quadriaxial carbon fabric $\left[0 \%+45^{\circ} / 90^{\circ} /\right.$ $\left.45^{\circ}\right]$ and polyamide 6 are $500 \mathrm{~g} / \mathrm{m}^{2}$ and $150 \mathrm{~g} / \mathrm{m}^{2}$, respectively. To specify the advantage of the $\mathrm{IH}$ system, test specimens were also moulded by a traditional hot press system. The moulding conditions of the specimens are shown in Table 1. The moulding temperature is set at $250{ }^{\circ} \mathrm{C}$ and the influence of the holding time at maximum temperature and the process on the mechanical properties will be discussed.

\subsection{Results and discussion}

Fig. 6 shows the bending strength of the specimens. From the results, the average bending strengths of specimens $\mathrm{IH} 2$ and $\mathrm{IH}-3$ are almost same, only about 60 seconds holding time at maximum temperature is needed for resin impregnation 
for the IH system. On the contrary, the traditional hot press requires not only a longer holding time but also a higher moulding pressure. The IH system can mould CFRTP products drastically faster than the traditional hot press method. The void content of specimens IH-2 and IH-3 is smaller than 5\%. As discussed in section 2.2 , carbon fibres heated by the IH system can also arrow resin to impregnate faster into the carbon fabrics.

Table 1: $\quad$ Moulding condition of the specimens.

\begin{tabular}{|c|c|c|c|c|c|}
\hline Specimen & $\begin{array}{l}\text { Holding time at } \\
\text { maximum } \\
\text { temperature (s) }\end{array}$ & Process & $\begin{array}{l}V_{f} \\
(\%)\end{array}$ & $\begin{array}{l}\text { Moulding } \\
\text { pressure } \\
(\mathrm{MPa})\end{array}$ & $\begin{array}{c}\text { Maximum } \\
\text { temperature } \\
\left({ }^{\circ} \mathrm{C}\right)\end{array}$ \\
\hline IH-1 & 0 & \multirow{3}{*}{ IH system } & \multirow{7}{*}{49} & \multirow{6}{*}{2.0} & \multirow{7}{*}{250} \\
\hline IH-2 & 30 & & & & \\
\hline IH-3 & 60 & & & & \\
\hline HP-1 & 120 & \multirow{4}{*}{ Hot press } & & & \\
\hline HP-2 & 300 & & & & \\
\hline HP-3 & 600 & & & & \\
\hline HP-4 & 300 & & & 4.0 & \\
\hline
\end{tabular}

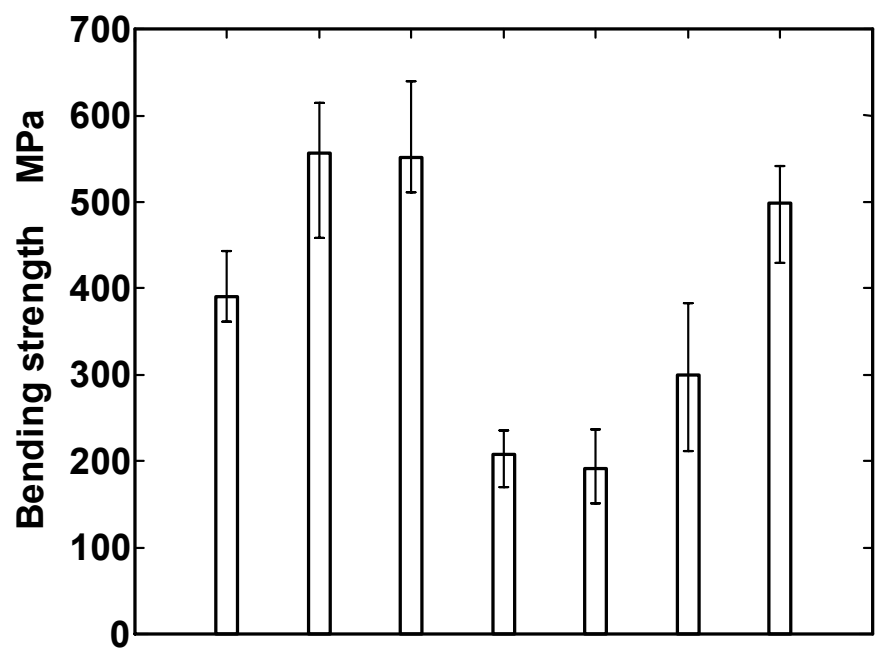

IH- 1 IH- 2 IH- 3 HP- 1HP- 2 HP- 3HP- 4

Figure 6: Bending strength of CFRTP $\left(\left[0^{\circ} /+45^{\circ} / 90^{\circ} /-45^{\circ}\right]_{2 \mathrm{~S}}\right)$.

\section{Conclusions}

A carbon fibre reinforced thermoplastics (CFRTP) process using high-speed processing by electromagnetic induction in combination with non-woven stitched multi-axial cloth (NSMC) was proposed in this study. Using our system, 
only about 60 seconds is needed to raise the mould temperature from $25^{\circ} \mathrm{C}$ to $250^{\circ} \mathrm{C}$, and the production cycle time is drastically reduced.

\section{References}

[1] Carney, Dan, Material issue, Automotive engineering international, August, pp. 55-58, 2005.

[2] Lomov, S. V., Belov, E. B., Bischoff, T., Ghosh, S. B., Truong, Chi T., Verpoest, I., Carbon composites based on multi-axial multi-ply stitched performs. Part 1. Geometry of the perform. Composites: Part A, 33, pp. 1171-1183, 2002.

[3] Truong, Chi T., Vettori, M., Lomov, S., Verpoest, I., Carbon composites based on multi-axial multi-ply stitched performs. Part 4. Mechanical properties of composites and damage observation, Composites: Part A, pp. 1207-1221, 2005.

[4] Guichard, A., Feigenblum, J., High-speed processing: using electromagnetic induction, JEC-Composites, pp. 94-96, 2004. 